\title{
Remote Control Smart Home System
}

\author{
Xianjie Feng \\ Department of architectural engineering dongguan university of technology, dongguan, 523808, China
}

\begin{abstract}
In this paper, SM8952AC25P, TC35i and photoelectric sensors for intelligent home system design. The hardware part of the system is mainly composed of control unit, sensor data acquisition system, TC35i interface and power supply. The MT8870 and the voltage sensing element are the key components of the control part of the system, which form part of the control function with the control unit. Sensor data acquisition system, TC35i and control unit to complete the alarm and other signal processing and transmission. The power supply section provides power for each part.
\end{abstract}

\section{Keywords-smart home system; TC35i; circuit desing}

\section{INTRODUCTION}

The function of smart home system is very complete[1,2], including smart lighting control system, electric curtain control system, background music system, security alarm control system, home appliance control system, central control system, intelligent control system, remote monitoring system, infrared sensing system, remote WEB management, intelligent fingerprint lock password, etc. Moreover, all of the above systems are independent, but also through the control of the host into a unified whole, and respond to each other, so that the real sense of intelligence. More convenient is not to increase any cost, use your hands on the iPhone or Android phone can also become a home control touch screen, whether at home or in the world, you can easily control your home. Let you experience the modern communications products and the perfect combination of the top smart home. Use the top smart home, you are about to experience the future of intelligent control.

\section{SMART HOME CONTROL SYSTEM STRUCTURE DIAGRAM}

The overall system block diagram structure shown in figure 1 , with the display control function of the central control panel we have a high performance, low power consumption characteristics, and no additional RF power amplifier. The system can achieve the following basic functions: remote signal receiver, the remote control system of air conditioning, stereo, etc for the remote control of home appliance, the Windows and doors should be equipped with mechanical and remote control system for furniture such as remote control. The central signal processing system can be compatible with different signals. In addition, also installed a feedback system, the entire system can be tested, and self-improvement[3].

\section{SMART Home System HARDWARE CIRCUIT DESIGN}

\section{A. Ringing Detection Circuit}

As shown in figure 2, the diode in this diagram has two functions:

Turn an uncertain line into a fixed positive and negative output; testing.

Turn the communication signal into a pulsating DC for

\section{B. Infrared Circuit Design}

Using RE200B as a thermal emission infrared sensor, BISS0001 is a signal acquisition and processing. When RE200B collects the human body signal, BISS0001 prints a high level, triode guide. The OUT end is low level. The OUT termination is connected to the P2.0 port. On the other hand, when there is no signal input, BISS0001 have no output signal low level, the transistor cut off, OUT is high.

In figure 3, the pyroelectric infrared sensor S-side output of an electrical signal, the electrical signal sent to the BISS001 the first 14 feet, that is, namely the first level of operational amplifiers OP1 in-phase input amplifier, and then sends this electrical signal to the bidirectional discriminator composed of COP1 and COP2 for voltage comparison, detects the effective trigger signal VS, starts the delay timing trigger.

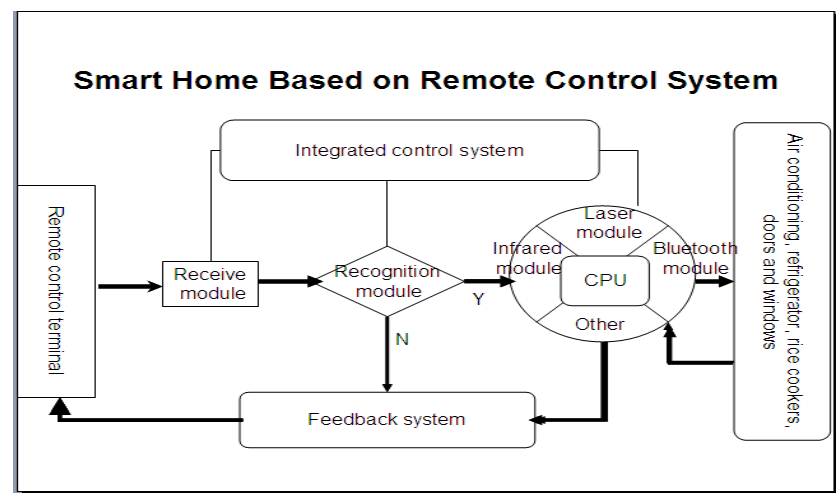

FIGURE I. FIGURE HEADINGS 


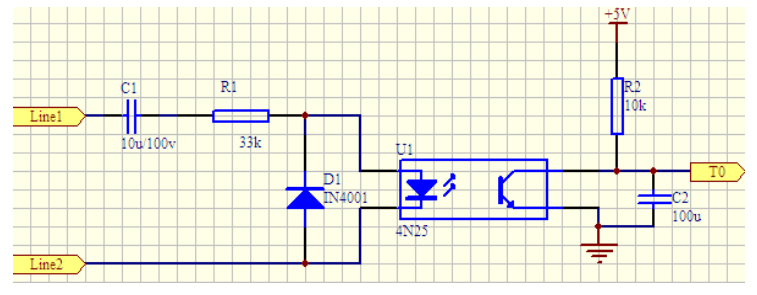

FIGURE II. RINGING DETECTION CIRCUIT

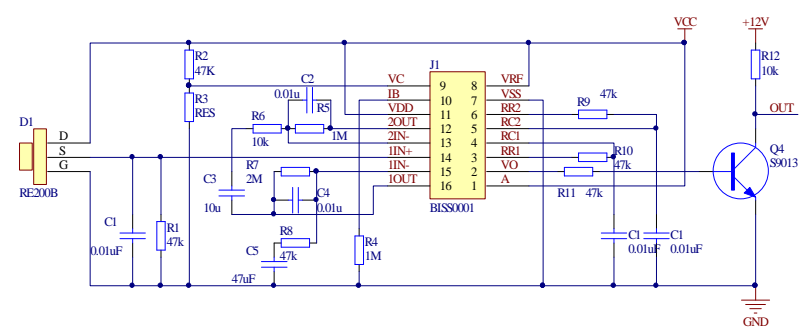

FIGURE III. INFRARED DETECTION CIRCUIT DIAGRAM

\section{TC35I MODULE AND MCU CONNECTION}

The data communication circuit mainly deals with short message receiving and receiving, communication with microcomputer, software flow control and so on. TC35 data interface using serial asynchronous transceiver, in line with ITU-T RS-232 interface circuit standard, working at CMOS level (2.65V). The data interface is configured as an 8-bit data bit, a 1-bit stop bit, no parity bit, and can run at a baud rate of $300 \mathrm{bps}$ to $115 \mathrm{kbps}$. The supported baud rate is $4.8 \mathrm{kbps}$ to 115 kbps (except $14.4 \mathrm{kbps}$ and $28.8 \mathrm{kbps}$ ). The TC35i also supports RTS0/CTS0 hardware handshaking and XON/XOFF software flow control.

Single-chip and TC35i generally use serial asynchronous communication interface, with infrared and communication cable two connection methods which level conversion and serial communication function to MAX3238 chip of TI company as the core, the communication speed can be set, usually 19200bps. The advantage of using infrared interface is that the single-chip system is electrically isolated from the mobile phone, and does not interfere with each other. The interface is independent and easy to use. The disadvantage is that the communication distance is short and the direction of infrared transmission is related to the relative position of the interface. When using cable connection, the reliability of data transmission is better[4].

When designing the system, in the face of all kinds of test objects, and a large number of control unit, need to use a variety of interface standards and MCU to connect, again through the MCU data processing, real-time measurement and control. At this time the use of single-chip to achieve intelligent home control system not only has the advantages of convenient collection, simple, flexible, and can greatly improve the coordination of the module and chip, thus greatly improving the system's availability. We integrated MT8870, TC35i modem and SM8952AC25P, the successful completion of the design requirements. And to achieve learning remote infrared remote control function, to control the infrared home appliances and equipment to provide a good foundation[5]. The system can also be applied to industrial and agricultural, to achieve unattended positions such as remote monitoring.

TC35i External Pin Circuit Shown in figure 4:

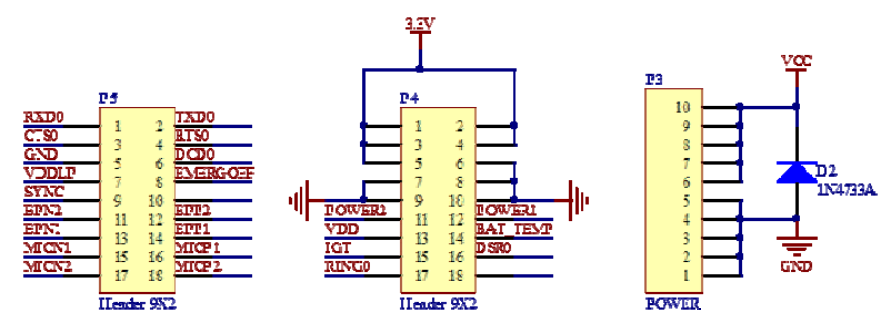

FIGURE IV. TC35I EXTERNAL PIN CIRCUIT

\section{TC35I POWER SUPPLy DESIGN}

TC35i power supply is mainly used LM2596 switching voltage regulator output $4.2 \mathrm{~V}$ voltage. LM2596 switching voltage regulator is a step-down power management monolithic integrated circuit that can output 3A drive current, while a very good linear and load regulation characteristics. The fixed output is $3.3 \mathrm{~V}, 5 \mathrm{~V}, 12 \mathrm{~V}$, which can produce any voltage less than $37 \mathrm{~V}$. The LM2596 internal integrated frequency compensation and fixed frequency generator, the switching frequency is $150 \mathrm{KHz}$. The shape and pin arrangement of LM2596 is shown in figure 5.

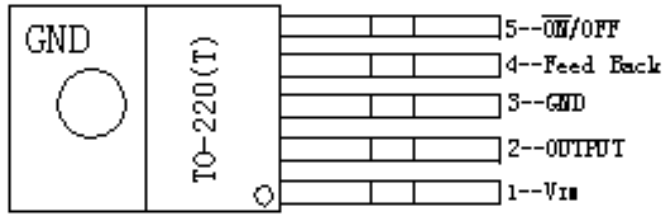

FIGURE V. LM2596 SHAPE AND PIN-OUT DIAGRAM

The TC35i power design mainly uses the LM2596 switch, voltage regulator to output the voltage of $4.2 \mathrm{~V}$ for TC35i. The circuit design principle is shown in figure 6.

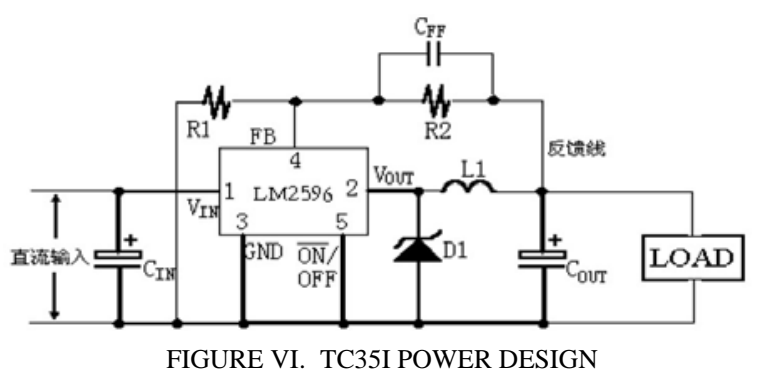

VI. IMPLEMENTATION OF SYSTEM RELATED FUNCTIONS

\section{A. SMS Controls Household Appliances}

Using a mobile phone to send text messages to the system, a single chip computer module, a single chip is controlled by a control relay to control $220 \mathrm{~V}$ home appliances, and send the text message with either phone. From this, we can control any 220V household appliance from our mobile phone, and make a whole smart home. 
During the summer, you can turn on the air-conditioner by text message, turn on the air-conditioner in the first 20 minutes, and enjoy the cool air conditioning when you get home.

You can control the rice cooker by using the smart home system and start cooking half an hour before you go home. You can go home and eat immediately[6].

\section{B. Anti - Theft Detection}

Smart home system contains an infrared detection device, when there are uninvited guests into your home, as long as the infrared probe is detected, to the owner to report the situation. At this time the owner will be from the control system SMS, the contents are:

There is an uninvited guest into your home!

Then you can timely alarm or home to see the situation.

So as to achieve the anti-theft function.

\section{SUMMARY}

Wireless solutions with good stability, low consumption, low radiation, scalable, high security performance become the most suitable wireless solution family. Smart home developers experienced from doubt, rejection, acceptance to welcome change, the domestic and foreign enterprises such as Philips, TCL, Haier, and other companies to join zigbee smart home camps. In the near future, there will be large-scale applications.

\section{ACKNOWLEDGEMENT}

This research is aided by following Dongguan Institute of Technology "The key technology research of the mobile WiMAX system ", which project number: 2008108101006.

\section{REFERENCES}

[1] Chris Cant. Pogramming development Guide of the windows driver model[M]. Beijing: Publishing House of Engineering Industry , 2005. 208-335.

[2] Chen L, Ozsu M T, Oria V. Robust and fast similarity search for moving object trajectories. In Proc. the ACM SIGMOD Int. Conf. on Management of Data, Baltimore, Maryland, 2005, pp.491-502.

[3] Don Anderson . Universal Serial Bus System Architecture. 2004. 277-287.

[4] Kwok-Wai Wong, Kin-Man Lam. An eficient algorithm for human face detection and facial feature extraction under different conditions. Pattern Recognition 34(2001).

[5] He yong yi. A Control System of Material Handling in FMS. Journal of shanghai university. Vol.1.No.1.1997.

[6] P.G. Clem, M. Rodriguez, J.A. Voigt and C.S. Ashley, U.S. Patent 6,231,666. (2001) 